\title{
Modeling Commercial Turbofan Engine Icing Risk With Ice Crystal Ingestion
}

Philip C. E. Jorgenson and Joseph P. Veres

Glenn Research Center, Cleveland, Ohio 


\section{NASA STI Program . . . in Profile}

Since its founding, NASA has been dedicated to the advancement of aeronautics and space science. The NASA Scientific and Technical Information (STI) program plays a key part in helping NASA maintain this important role.

The NASA STI Program operates under the auspices of the Agency Chief Information Officer. It collects, organizes, provides for archiving, and disseminates NASA's STI. The NASA STI program provides access to the NASA Aeronautics and Space Database and its public interface, the NASA Technical Reports Server, thus providing one of the largest collections of aeronautical and space science STI in the world. Results are published in both non-NASA channels and by NASA in the NASA STI Report Series, which includes the following report types:

- TECHNICAL PUBLICATION. Reports of completed research or a major significant phase of research that present the results of NASA programs and include extensive data or theoretical analysis. Includes compilations of significant scientific and technical data and information deemed to be of continuing reference value. NASA counterpart of peer-reviewed formal professional papers but has less stringent limitations on manuscript length and extent of graphic presentations.

- TECHNICAL MEMORANDUM. Scientific and technical findings that are preliminary or of specialized interest, e.g., quick release reports, working papers, and bibliographies that contain minimal annotation. Does not contain extensive analysis.

- CONTRACTOR REPORT. Scientific and technical findings by NASA-sponsored contractors and grantees.
- CONFERENCE PUBLICATION. Collected papers from scientific and technical conferences, symposia, seminars, or other meetings sponsored or cosponsored by NASA.

- SPECIAL PUBLICATION. Scientific, technical, or historical information from NASA programs, projects, and missions, often concerned with subjects having substantial public interest.

- TECHNICAL TRANSLATION. Englishlanguage translations of foreign scientific and technical material pertinent to NASA's mission.

Specialized services also include creating custom thesauri, building customized databases, organizing and publishing research results.

For more information about the NASA STI program, see the following:

- Access the NASA STI program home page at http://www.sti.nasa.gov

- E-mail your question to help@sti.nasa.gov

- Fax your question to the NASA STI Information Desk at 443-757-5803

- Phone the NASA STI Information Desk at 443-757-5802

- Write to: STI Information Desk NASA Center for AeroSpace Information 7115 Standard Drive Hanover, MD 21076-1320 


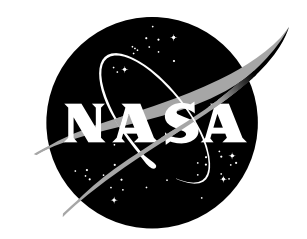

\section{Modeling Commercial Turbofan Engine Icing Risk With Ice Crystal Ingestion}

Philip C. E. Jorgenson and Joseph P. Veres

Glenn Research Center, Cleveland, Ohio

Prepared for the

5th Atmospheric and Space Environments Conference

sponsored by the American Institute of Aeronautics and Astronautics

San Diego, California, June 24-27, 2013

National Aeronautics and

Space Administration

Glenn Research Center

Cleveland, Ohio 44135 


\section{Acknowledgments}

This work is supported by the NASAAtmospheric Environment Safety Technologies (AEST) Project in the NASAAviation Safety Program (ASP), and is in response to the Engine Icing Technical Challenge. We would like to thank Dr. Renato Colantonio, manager of the NASA AEST Project, under the ASP, for supporting this work. We would also like to acknowledge Dr. Michael Oliver, Dr. Judith Foss Van Zante, Timothy Bencic, Amy Fagan, Christopher Lynch, Bryan Rosine, Tom Griffin, Queito Thomas, Jonathan Paul Kirkegaard, Dennis Dicki, Paul Lizanich, Steve Pesek, Pamela Poljak, Kent A. Smith, and the rest of the Propulsion Systems Laboratory (PSL) technicians and engineers that supported the test and facility development at NASA Glenn Research Center for providing the excellent test data for this engine in the unique altitude test facility with spray bars that successfully simulated ice ingestion testing. We also acknowledge the help and guidance we received from Dr. William B. Wright, Vantage Partners, LLC. for guidance in providing the MELT code, Mr. Scott Jones, NASA Glenn Research Center, in the use of the engine cycle code, and Dr. Jen-Ching Tsao, Ohio Aerospace Institute, for his insights and analyses.

Level of Review: This material has been technically reviewed by technical management.

Available from

NASA Center for Aerospace Information 7115 Standard Drive

Hanover, MD 21076-1320
National Technical Information Service 5301 Shawnee Road Alexandria, VA 22312 


\title{
Modeling Commercial Turbofan Engine Icing Risk With Ice Crystal Ingestion
}

\author{
Philip C. E. Jorgenson and Joseph P. Veres \\ National Aeronautics and Space Administration \\ Glenn Research Center \\ Cleveland, Ohio 44135
}

\begin{abstract}
The occurrence of ice accretion within commercial high bypass aircraft turbine engines has been reported under certain atmospheric conditions. Engine anomalies have taken place at high altitudes that have been attributed to ice crystal ingestion, partially melting, and ice accretion on the compression system components. The result was degraded engine performance, and one or more of the following: loss of thrust control (roll back), compressor surge or stall, and flameout of the combustor. As ice crystals are ingested into the fan and low pressure compression system, the increase in air temperature causes a portion of the ice crystals to melt. It is hypothesized that this allows the ice-water mixture to cover the metal surfaces of the compressor stationary components which leads to ice accretion through evaporative cooling. Ice accretion causes a blockage which subsequently results in the deterioration in performance of the compressor and engine. The focus of this research is to apply an engine icing computational tool to simulate the flow through a turbofan engine and assess the risk of ice accretion. The tool is comprised of an engine system thermodynamic cycle code, a compressor flow analysis code, and an ice particle melt code that has the capability of determining the rate of sublimation, melting, and evaporation through the compressor flow path, without modeling the actual ice accretion. A commercial turbofan engine which has previously experienced icing events during operation in a high altitude ice crystal environment has been tested in the Propulsion Systems Laboratory (PSL) altitude test facility at NASA Glenn Research Center. The PSL has the capability to produce a continuous ice cloud which are ingested by the engine during operation over a range of altitude conditions. The PSL test results confirmed that there was ice accretion in the engine due to ice crystal ingestion, at the same simulated altitude operating conditions as experienced previously in flight. The computational tool was utilized to help guide a portion of the PSL testing, and was used to predict ice accretion could also occur at significantly lower altitudes. The predictions were qualitatively verified by subsequent testing of the engine in the PSL. The PSL test has helped to calibrate the engine icing computational tool to assess the risk of ice accretion. The results from the computer simulation identified prevalent trends in wet bulb temperature, ice particle melt ratio, and engine inlet temperature as a function of altitude for predicting engine icing risk due to ice crystal ingestion.
\end{abstract}




\section{Introduction}

$\mathrm{T}$ HERE have been numerous reported engine icing events ${ }^{1}$ that have occurred on commercial airlines (Figure 1) during flight through clouds with high ice water content. These events have been attributed to ice crystal ingestion and subsequent ice accretion (hereafter referred to as ice accretion) and are thought to occur on the stationary parts in the region of the low pressure compressor. The total number of engine icing events per year appears to be increasing since $2002^{2}$.

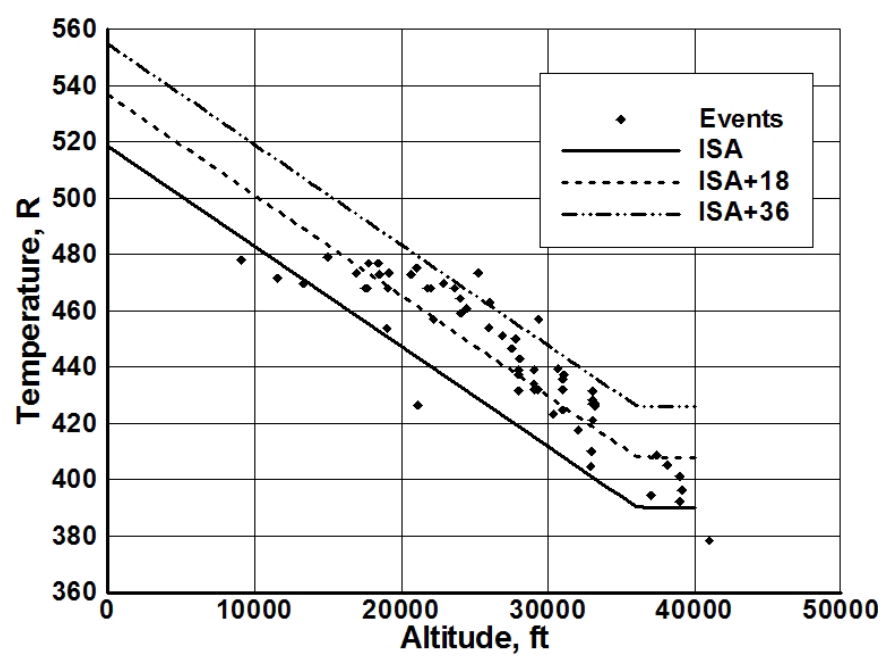

Figure 1: Reported engine icing events. The engine events occurred at altitudes between $10 \mathrm{~K}$ and $40 \mathrm{~K}$ feet and at temperatures between ISA and ISA+36R.

A computational tool ${ }^{3,4}$ has been developed with the capability to analyze the performance of a turbine engine as it ingests ice crystals while flying through an ice cloud at altitude conditions. The tool can be used to evaluate the susceptibility of turbine engines to ice accretion. The tool has an engine system thermodynamic cycle code, a compressor flow analysis code, a fluid properties code, and an ice particle melt code. The mixed fidelity computational tool provides details of the flow conditions within each blade row of the fan and low pressure compression system (LPC) during operation in the engine system environment. Ice accretion in the LPC reduces the available aerodynamic area and deteriorates the performance of the compressor, and consequently on the overall performance of the engine. In this paper the performance loss of the compressor due to accretion is not addressed, since the focus is on the risk of ice accretion. However, ice accretion can result in uncommanded reduction in thrust, compressor surge, and combustor flameout ${ }^{1}$.

In this study a turbofan engine is modeled at the altitude, vehicle flight Mach number, ambient temperature and engine thrust level where it has been known to experience an icing event that was attributed to ice accretion in the low pressure compressor. Note that this engine model is no longer in service, and has been replaced with a new version which does not experience any icing events. The original engine that did experience icing events was procured, installed, and tested in the Propulsion Systems Laboratory (PSL) altitude test facility at NASA Glenn Research Center in the month of February, 2013. The test facility is equipped with water spray bars capable of producing an ice crystal cloud that simulates the ice clouds at high altitudes. The engine was tested over a range of conditions, including the flight altitudes, Mach number, and fan speeds where it had experienced uncommanded thrust reduction due to ice accretion in the low pressure compressor stator region. During testing in the PSL at simulated altitude conditions, engine icing event was duplicated successfully at operating points where it previously experienced an icing event during flight. The purpose of this research is to apply an engine icing computational tool to simulate the flow through the turbofan engine in order to determine the wet bulb temperature and ice particle melt ratio through the LPC flow path, at the selected data points that were obtained in the PSL. The computational tool was utilized to increase understanding of the flow field within the low pressure compressor at numerous operating conditions that resulted in ice accretion. During the PSL engine testing, the computational tool was used to suggest additional operating points at lower altitudes where the there is a risk of ice accretion, other than the altitudes where 
there it experienced icing events in flight. These additional operating conditions were then tested in PSL and engine ice accretion was encountered at operating conditions close to those predicted with the modeling tool.

\section{Engine / Compressor Modeling Codes}

The computational tool that has been utilized to analyze the engine at the selected test points in this study is the customer deck (CD) engine thermodynamic cycle code that was obtained from the engine manufacturer, and the mean line compressor flow analysis code ${ }^{5}$. The code includes a fluid properties model to account for supplemental water vapor in the air. Additionally, the computational tool incorporates a code named MELT to model the melting of ice particles. This code leverages capabilities from the LEWICE2D code ${ }^{6,7}$. These codes have been coupled together such that they exchange boundary conditions at each iteration. The compressor analysis code computes the detailed blade row by blade row flow conditions, as well as the overall compressor performance. The MELT code has been developed to compute the melting rate of ice crystals, as they pass through the engine inlet, fan and low pressure compressor blade rows. The models for sublimation, melting, and evaporation in the MELT code have been adapted from the LEWICE2D code; however, there are no models for ice accretion, particle breakup, shedding, or erosion in MELT. The compressor code, COMDES ${ }^{5}$, and MELT have been coupled to exchange boundary conditions at the blade leading and trailing edges. The compressor code has a model to calculate the effects of water vapor on the fluid properties of the air - water vapor mixture based on the mole fraction of air to water vapor. The local relative humidity is computed through each component of the inlet-fan-LPC, taking the sublimation, melting, and evaporation into consideration, as well as the local static temperature of the air. The resulting performance of the compressor is computed based on air fluid properties with humidity.

\section{A. Aerothermodynamic Simulation of the Engine System; Customer Deck and Compressor Flow Model}

The customer deck (CD), that models the aerothermodynamic performance of the turbofan engine, was obtained from the engine manufacturer. The CD code provides the overall component-level performance and flow conditions of pressures and temperatures, as illustrated in Figure 2. The fan is split into two distinct regions, the fan tip which models the flow through the bypass, and the fan core, which includes the low pressure compressor (supercharger). The CD system modeling code is comprised of component characteristic maps for each major engine component, and does not have the fidelity to provide the flow conditions within the stages and blade rows. Therefore a mean line compressor flow code, COMDES, was utilized to provide the flow conditions at a higher fidelity within each blade row of the multi-stage fan-core and low pressure compressor.

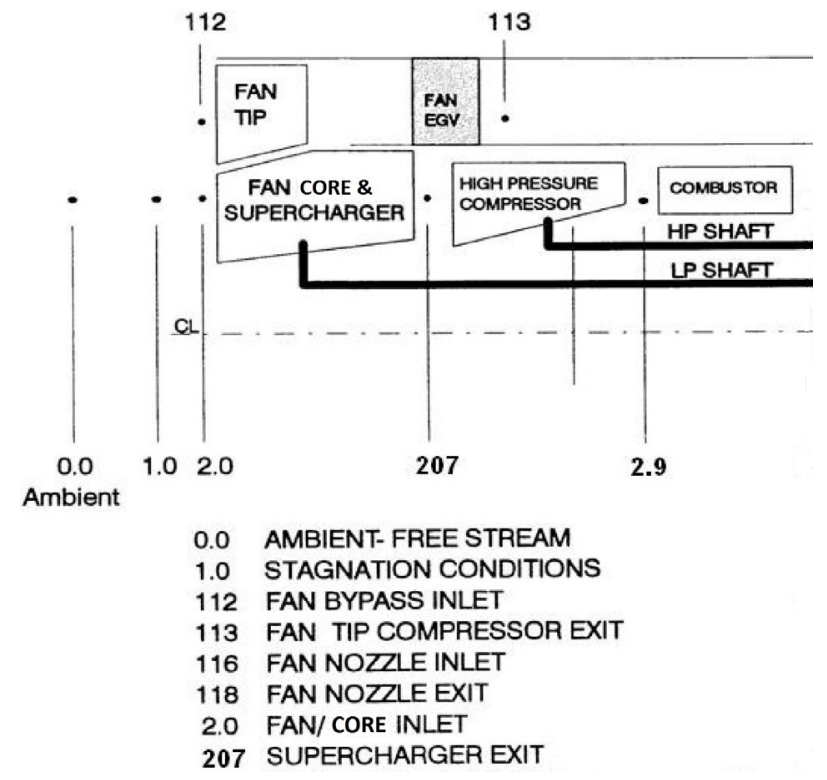

Figure 2: The engine block diagram of the two spool turbofan engine, as modeled in the Customer Deck (CD).

The inputs provided to the $\mathrm{CD}$ system modeling code are the altitude, flight Mach number, fan physical rotational speed, and the air static temperature. The model results include the aerothermodynamic performance of each major 
engine component, as described in Figure 2, including the bypass ratio. The main purpose of the $\mathrm{CD}$ engine system model was to provide the bypass ratio and thus, the air mass flow into the engine core.

The COMDES and the CD system codes were utilized such that the boundary conditions from the CD at each operating point were passed as inlet boundary conditions to the compressor flow analysis code. The block diagram in Figure 3 illustrates the process by which the boundary condition data is transferred between the CD system model and the mean line flow analysis code. The codes are outlined with the rectangular shaped border, while the boundary condition information passed between the codes have borders with rounded corners.

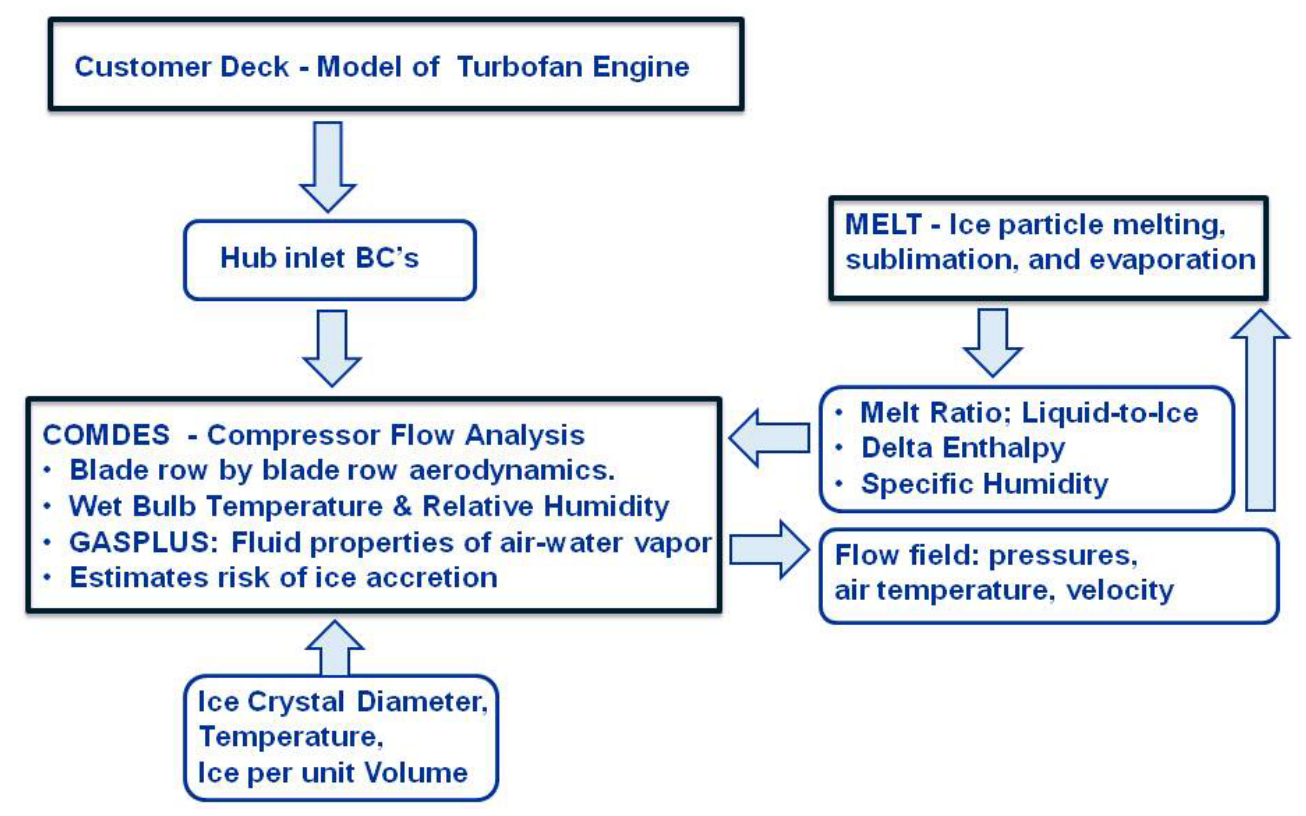

Figure 3: The CD engine system model, COMDES $^{5}$ compressor flow model and MELT computer model boundary exchange strategy for the fan-core and LPC. GASPLUS ${ }^{8}$ is the fluids properties code. The fan-core and LPC performance is computed with the COMDES code, and the MELT code.

The CD was executed first and provided the calculated air mass flow rate into the engine core, as well as the inlet total temperature and pressure for a given engine operating point. The next step in the process was to execute the compressor analysis code to obtain the detailed blade row by blade row flow analysis of the fan-core and LPC in the engine system environment, including the local pressure and temperature between each rotor and stator blade rows. Additional parameters that were calculated by the compressor model include the wet bulb temperature, and the ice particle melt ratio, which is the local value of the liquid water to the total water ratio (ice + water), referred to in this study as the ice particle melt ratio.

The COMDES flow code computes the velocity, pressure, temperature, and flow angles at the leading edge and trailing edge of each blade row, at the hub, mean, and tip sections. The mean line compressor flow analysis code has been modified to include the effects of relative humidity on the fluid properties of air and water vapor mixture, and the subsequent effects on compressor performance. The capability to calculate the local relative humidity in each blade row is based on the initial value of specific humidity (mass of water/mass of air) at the engine inlet, as well as the sublimation and evaporation of the particles through the flow path. Additional modifications have been made to enable calculating the two key parameters which have been identified as indicators of the risk of ice accretion: the local wet-bulb temperature and the ice particle melt ratio. These parameters are calculated at each blade row. If the limiting values of these key parameters are met, there is a risk that ice will accrete on the surfaces of the compressor. With these parameters as the precursors to the risk of ice accretion, the blade row within the compression system can be identified that is likely to experience ice buildup at a particular engine operating condition.

The ice particle melting and evaporation model, MELT, computes the local ice particle melt ratio and calculates the change of phase of an ice particle as it sublimates, melts, and eventually evaporates, as it passes through the various components of the engine, starting at the engine inlet and through the fan and low pressure compressor blades and 
stator vanes. The ice particle residence times through each component are estimated based on the velocities at the inlet and exit of the component and the distance the particle travels. The components are the engine inlet, each rotor and stator blade, support strut, and the axial gaps between the rotors, stators and the struts. The MELT code provides a calculated value of the residence times of the ice particles through each blade passage and gap, resulting in an estimate of the sublimation, melting, and evaporation. The specific humidity, the ice water concentration (IWC), and particle diameter are specified at the inlet to the engine. Since there is no particle breakup model in the MELT code, the value for ice particle diameter in this study is assumed to be $5 \mu \mathrm{m}$, while the particle concentration are specified from test data. After the flow conditions through the blade rows have been calculated by COMDES, the static temperatures, pressures, and velocities are passed to MELT to determine the rate of melting and evaporation, and thus, the local ice particle melt ratio in each blade row. The calculations for sublimation, melting, and evaporation take into consideration the local static temperatures, pressures, and residence times as they traverse through the engine inlet, the fan-core and low pressure compressor blade passages and gaps at the mid span location, the gooseneck duct and the support strut.

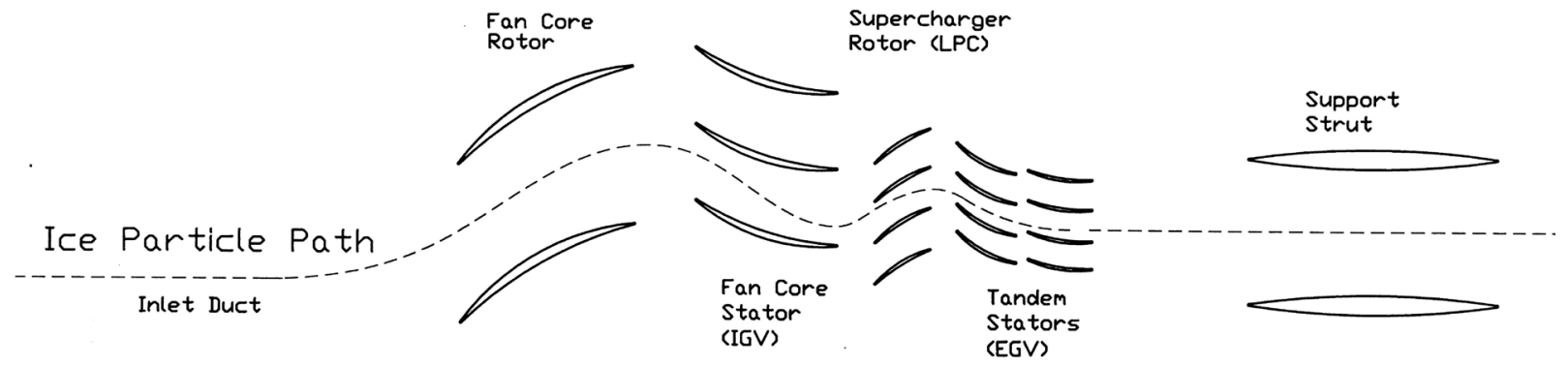

Figure 4: Ice particle path through the inlet, fan-core and supercharger stage, and support strut. The distance traveled by the particle is estimated from the rotor and stator mean camber chord length at the mid-span.

Figure 4 shows a simplified illustration of the ice particle path through the rotor blades in the relative frame of reference, while the path through the stator vanes is in the absolute frame of reference. The calculations of ice sublimation, melt, and evaporation are performed in increments from the leading to the trailing edge of each rotor and stator, as well as through the axial gap between the blades, as a function of velocity and distance traveled. The distances traveled are assumed to be equal to the chord length of each rotor and stator, as well as the gap between rotor and stator. The amount of water due to sublimation and evaporation is added to the local value of specific humidity, thus having an effect on the local relative humidity, and likewise on the local wet-bulb temperature calculation in the compressor code.

\section{B. Ice Accretion Risk Criteria}

The targeted area in this engine where ice accretion is suspected to initiate has been identified by the manufacturer as the tandem stator (EGV) region. Based on preliminary experimental findings of ice accretion on an airfoil at the National Research Council of Canada (NRCC) ${ }^{9,10}$, in order for ice accretion to occur, the wet-bulb temperature was set to a value several degrees Celsius above, or below the freezing temperature of water. The other key parameter for ice accretion was found to be the local ice particle melt ratio. These two parameters are considered to be the necessary conditions which must be met simultaneously at the same location in the compressor, in order for there to be a risk of ice accretion. Based on observations that were made from the laboratory test data ${ }^{9}$, an ice particle melt ratio in the vicinity of $10 \%$ or greater was considered a requirement in order for accretion to occur. However, in this study, the values for these two parameters were determined in the targeted region from the flow analysis of the fan and LPC at the test data points where this engine experienced ice accretion during PSL testing. The results of the analyses relaxed the ice accretion requirements, allowing for higher wet bulb temperatures and a lower ice particle melt ratio limit for this engine, in comparison to the NRCC observations. Since the wet-bulb temperature and the ice particle melt ratio both change through each blade row, this technique also identifies the blade row where there is a risk of ice accretion. It is recognized that other parameters such as the heat transfer rate through the blades and flow path walls need to be considered as well, but are not included in the current version of the compressor flow analysis code. It is assumed in this study that accretion due to ice crystals does not occur on compressor rotors. Therefore the 
assumption is that accretion can only occur on the stator vanes and flow path walls, including downstream of the last stator of the LPC.

\section{Icing Risk Analysis of a Turbofan Engine with Ice Crystal Cloud Ingestion}

\section{A. Ice Crystal Particle vs. Air Temperature through the Engine Inlet in a Direct Connect Facility}

The computational flow modeling to determine the icing risk of the engine starts at the direct connect duct flange of the PSL test facility. The engine tested was connected to the PSL test facility in a "direct connect" manner. The pipe supplying the air flow is connected to the engine flange, as illustrated in Figure 5. In this sense, the engine does not have a typical flight inlet nacelle, but does feature a section of pipe that acts as an "inlet" which diffuses the flow ahead of the fan face. The PSL test facility has been calibrated over a limited range of altitudes and temperatures to provide known flow conditions and glaciated ice crystals at the inlet of this inlet duct. The computer flow analysis in this study begins at the entrance of this duct, and continues through the fan core, LPC, and support strut.

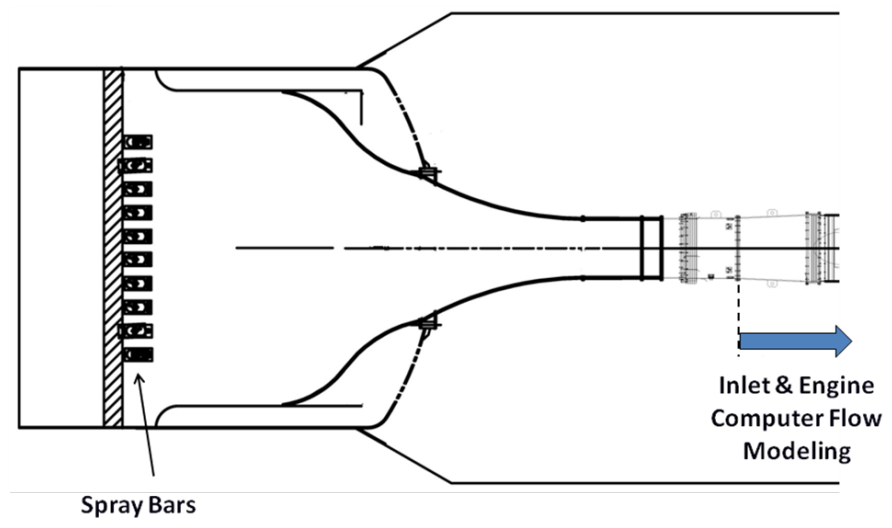

Figure 5: Inlet duct in the PSL test facility connects directly to the engine inlet flange.

The "flight" Mach number that is being simulated in the tunnel is utilized to calculate the relation between the static and total temperature at the inlet of the inlet duct. At the inlet, the temperature of the ice crystals is assumed to be equal to the static temperature of the air at the simulated flight Mach number. However, because of a moderately high flight Mach number, the total temperature of the air is higher. As the air is diffused through the subsonic inlet, the static temperature of the air rises before reaching the fan leading edge, and the temperature of the ice particle likewise increases. At high altitude operating conditions the temperature of the ice particles through the engine inlet is typically well below freezing, until the particles are inside the fan-core and LPC, where it rises rapidly, due to the energy addition by the rotors. Figure 6 illustrates the computed temperature rise of the particle as it travels through the direct connect inlet duct and the fan-core and LPC, for a typical high altitude operating point.

Although the computer code (COMDES) models the air flow and ice crystal physics through the inlet duct portion of the engine, the subsequent figures will focus on illustrating the flow conditions of wet bulb temperature and ice particle melt ratio in the fan-core and LPC, since those are the regions where there may be a risk of accretion due to ice crystals. 


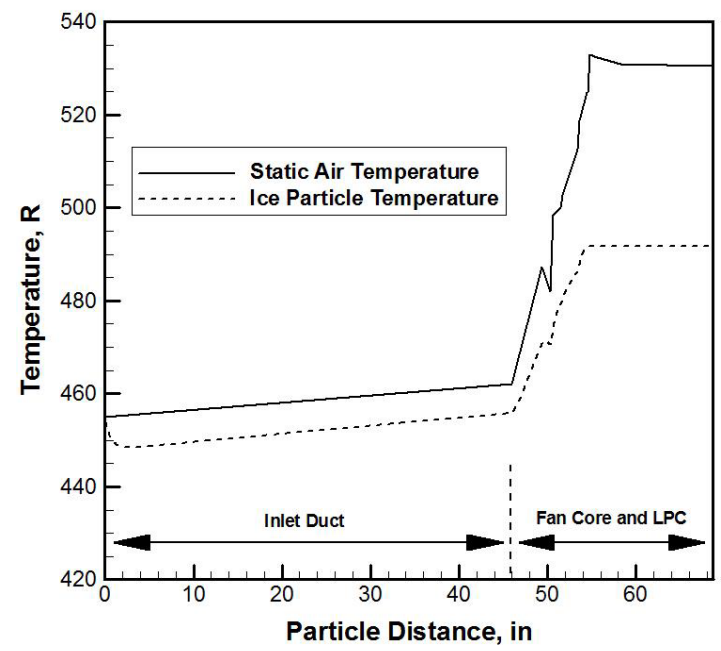

Figure 6: The computed temperature rise of the ice crystal particle lags behind the local static temperature of the air. In this example, the ice particle temperature is below $492 \mathrm{R}$ through the inlet duct.

\section{B. Icing Risk Analysis of the Fan Core and Low Pressure Compressor.}

In order to perform the aerothermodynamic flow analysis of the engine that was tested in the PSL, it was necessary to obtain the detailed geometry of the low pressure compressor (LPC) such that the flow conditions between each blade row could be computed with the mean line compressor flow code. Figure 7 illustrates a notional representation of the fan and low pressure compressor cross section of the turbofan engine tested in the PSL. Note that there is a notional streamline that is utilized in the compressor flow code that represents the cutwater between the air flow that enters the fan bypass duct, and the flow that enters the core. This streamline separates the outer bypass flow from the core flow and is utilized in the mean line model as the outer flow path wall of the fan-core. This engine features a heated spinner and a heated fan core stator row (inlet guide vane) shown in Figure 7. The tandem stators in the low pressure compressor stage (exit guide vanes - EGV) are also shown in the figure.

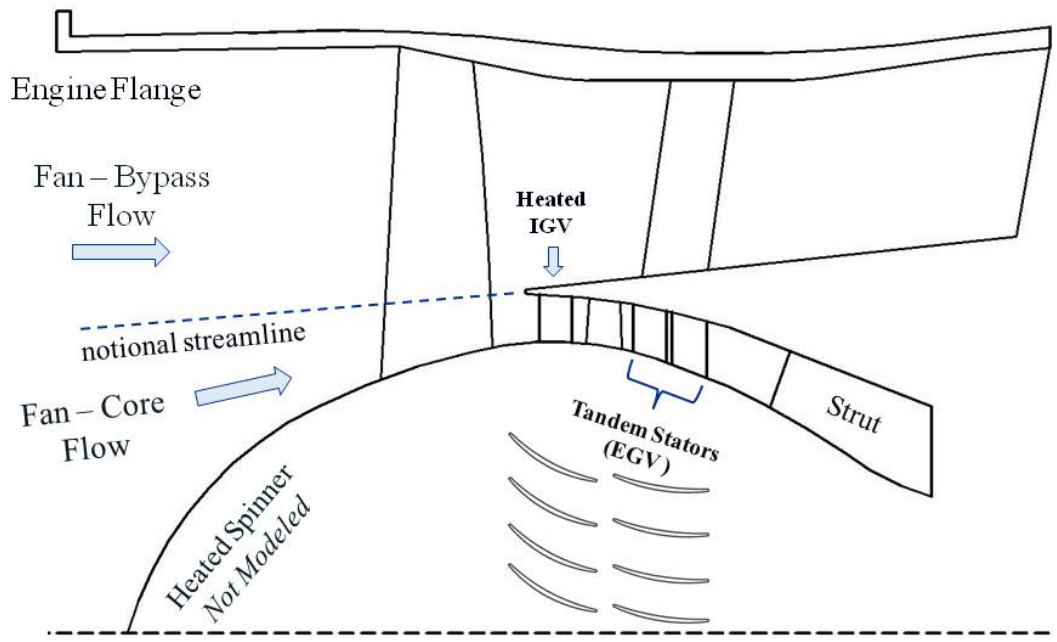

Figure 7: Schematic of the fan and low pressure compressor portion of the engine tested in the PSL with ice crystal ingestion.

During the testing with the ice cloud on, the engine experienced numerous uncommanded thrust reductions. However, there were also data points where the engine did not experience ice accretion even when the particle concentration was increased. From the test data that was generated in PSL, representative operating points were selected for flow analysis, utilizing the computer models described in Section I. An engine icing event caused by ice accretion was defined by the test engineers as the point where the engine thrust was observed to decrease to a 
reduced value ( $\sim 93 \%$ of load cell value before the ice cloud initiation), indicating that full engine roll back would have been imminent if the testing with the ice cloud on had been continued. This was done to reduce the amount of ice accretion, and to protect the engine from subsequent potential ice shedding damage.

This analysis considers the source of liquid water due to the partial melting of the ice particle by the air through the heat of compression. Other sources of liquid water may be present in the flow field as well that are currently not accounted for in the computer modeling. This engine has a heated spinner and heated inlet guide vane (stator) which are potentially additional sources of liquid water. The CD engine system model analysis does take into consideration the addition of compressor discharge air that heats the stator row (inlet guide vane) as shown in Figure 7. This small amount of compressor discharge air is mixed with the core flow, resulting in a slight increase in the bulk temperature of the air entering the core, and therefore has an effect on the inlet temperature utilized in the compressor flow analysis.

The analysis tool was executed at the operating conditions where the engine icing events occurred on the PSL test stand. The altitude, vehicle Mach number, fan rotational speed, and ambient temperature were specified in the engine model. For this analysis, the ice particle concentration values prescribed during the PSL testing were used in the flow analysis computer model. Since there is currently no ice particle break up model in the compressor flow analysis code, the ice particle size utilized in this study was set at $5 \mu \mathrm{m}$. This particle size was found to be the most susceptible to providing a non-zero ice particle melt ratio during the operating points that resulted in an engine icing event which was caused by ice accretion in the region of the LPC. To determine the risk of ice accretion the flow analysis of the fan-core and low pressure compressor was computed at the specific operating condition just seconds prior to the ice cloud initiation.

\section{Engine Data Points with Ice Accretion}

Several test data points that resulted in ice accretion were analyzed with the CD engine system model and the compressor flow analysis code. The existence of liquid water in the air appears to be an important factor in causing ice accretion. As previously mentioned, this analysis addressed the source of liquid water from melting of the ice particle due to warm air caused by the heat of compression. Other sources of heat that are not modeled in this analysis that could potentially add liquid water to the air are the heated spinner and the heated inlet guide vane, which is an anti-ice feature.

The streamwise distribution of local static temperature along the flow path and the ice particle residence time in the rotor blades, stator vanes, and gaps are two important parameters that determine the ice particle melt ratio due to heating by the air. Figure 8 shows the flow analysis results illustrating the streamwise distribution of wet bulb temperature and the ice particle melt ratio.

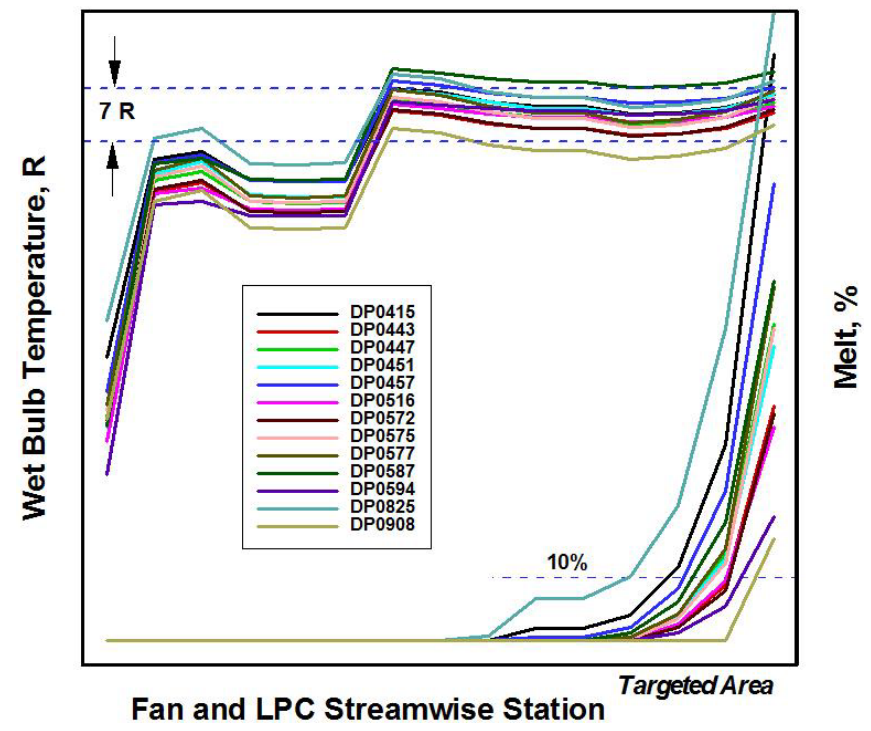

Figure 8: Flow analysis of the fan-core and LPC stage at the test data points which experienced ice accretion, showing the calculated wet bulb temperature and ice particle melt ratio. 
For the points in the above figure the range of wet bulb temperatures in the low pressure compressor second tandem stator is in a narrow range of 7 Rankine. The local static temperature affects the ice particle melt ratio of the ice particle. For these test points the typical ice water content (IWC) flow rate was less than $3 \mathrm{~g} / \mathrm{m}^{3}$. The computer flow analysis shows that for these test points, the amount of liquid water due to the heating by the air has a definite contribution to the total amount of melted water in the flow path. As a consequence the existence of liquid water due to heating by the air appeared to have made the difference between ice accretion and no ice accretion in the example test data points studied. In most of the cases with ice accretion, the ice particle melt ratio due to heating by the air at the tandem stator trailing edge was in the range of $2 \%-21 \%$. The targeted area where ice accretion is suspected to initiate is the tandem stator (EGV) region. In some cases with ice accretion, the ice particle melt ratio due to heating by the air reached $100 \%$ by the time the particle reached the support strut exit. Further analyses, including multidisciplinary simulation of more detailed test data, are needed in order to better understand the possible effect of all sources of heat in this engine on the ice crystal melting process.

\section{Example Data Point with Ice Accretion (DP0457)}

Figure 9 shows the analysis results of DP0457 which is representative of an operating point in which the engine experienced ice accretion. The results from the CD system model was utilized to provide the inlet flow conditions for the fan core and LPC simulation with the COMDES flow analysis code. The results of the CD engine system model and the measured values for key engine parameters at DP0457 compared well, and were on the order of 1\%. Therefore the flow modeling with the COMDES flow code was considered to be an accurate representation of the actual conditions in the compressor at this data point, prior to ice cloud on. The modeling results for the wet bulb temperature distribution and the ice particle melt ratio through the flow field were obtained from the flow analysis. The wet bulb temperature at the tandem stator exit falls within the 7 Rankine range, as illustrated in Figure 9, with a value of ice particle melt ratio of $8.1 \%$ at the targeted area of interest, the tandem stator trailing edge.

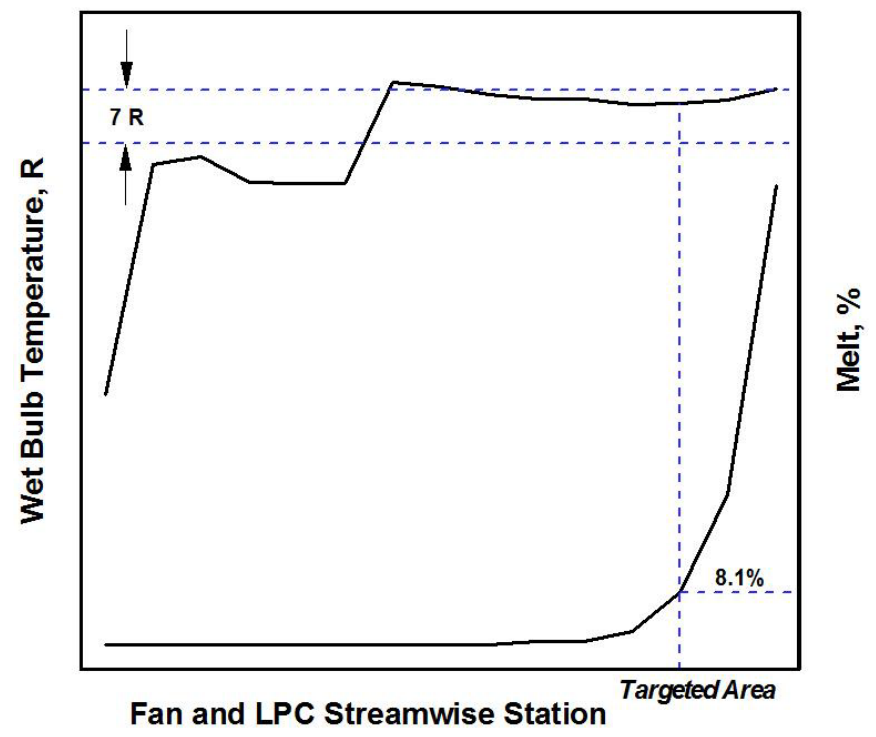

Figure 9: Flow analysis results of a typical data point with ice accretion (DP0457), showing the wet bulb temperature (left) and the ice particle melt ratio (right) near the targeted area of interest.

Figure 10 illustrates the calculated values for total, static, and wet bulb temperature distributions through the fancore and LPC for this data point, before the ice cloud was turned on. At the tandem stator trailing edge the calculated total and static air temperatures are well above freezing, and support ice particle melting in the tandem stator and support strut regions. The engine instrumentation also included thermocouples on both of the EGV tandem stator vanes 1 and 2 close to the outer flow path near the leading and trailing edges (Figure 7). The metal temperature measurements are superimposed on the calculated air temperature plot in Figure 10, before the ice cloud was turned on, and are located between the calculated values of air static and total temperatures. This shows qualitatively that the air temperatures from the computational flow analysis are reasonable. There was some circumferential variation in measured metal temperatures, as indicated by the bars. After the ice cloud was turned on, the stator metal temperatures quickly decreased. 


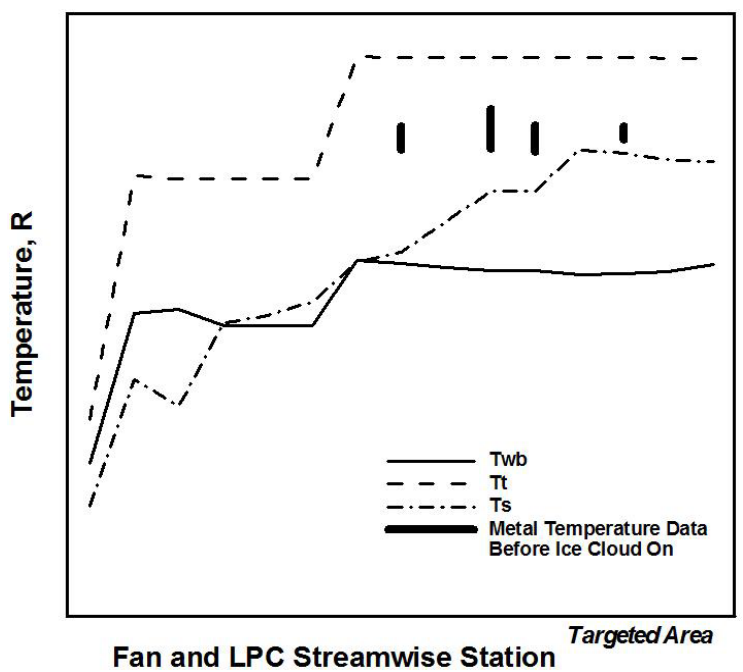

Figure 10: Computed flow analysis results of a typical data point with ice accretion (DP0457) showing the wet bulb, static, and total temperatures of the air in the LPC, as well as the measured metal temperatures in the EGV.

\section{Computer Flow Analyses of Data Points where the Engine Experienced Ice Accretion}

After successfully experiencing ice accretion in the engine at high altitudes in the PSL, it was proposed to exercise the test facility to investigate whether the engine could be made to experience ice accretion at lower altitude operating points. Note that the lower altitudes were outside the calibration envelope of the tunnel, Figure 11. The computer model was utilized to determine the required engine inlet temperature in order for ice accretion to occur at the lower altitudes. The range of altitudes where ice accretion in the engine was predicted spanned $30 \mathrm{~K}$ feet. Two criteria were utilized to predict the conditions under accretion would occur at these lower altitudes. First, the engine inlet temperature was determined that would result in a wet bulb temperature at the targeted area that was within the narrow 7 Rankine range which was deduced from the analysis of data points shown in Figure 8 . The second criterion was that the ice particle melt ratio had to be non-zero at the same location in the targeted area, also illustrated in the figure. Subsequent testing in the PSL facility confirmed ice accretion at these predicted lower altitude data points. Figure 11 illustrates the engine inlet temperature in terms of offset from the international standard atmosphere (ISA) temperature, versus altitude where the engine experienced ice accretion. The ISA offset temperature had a range of 126 Rankine throughout the tested altitude range of $30 \mathrm{~K}$ feet.

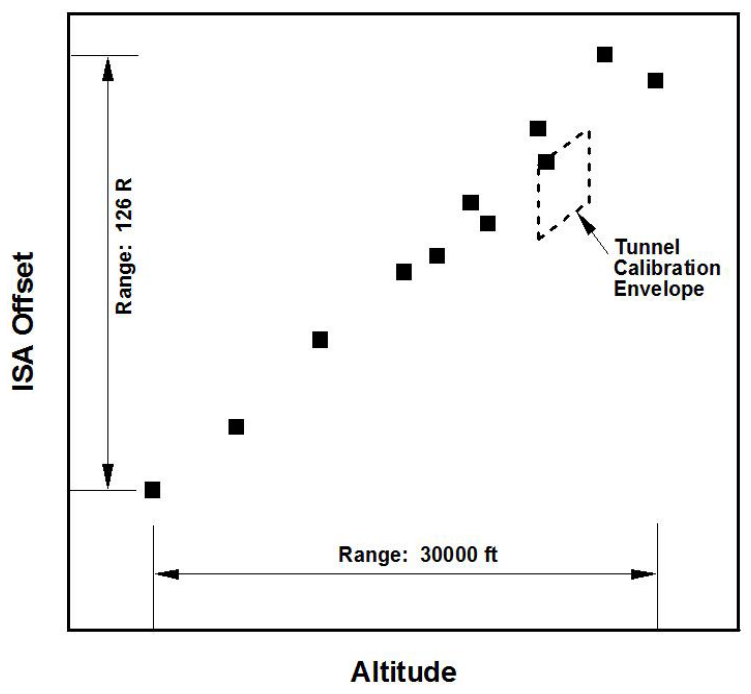

Figure 11: Engine inlet temperature in terms of the ISA offset, versus altitudes where the engine experienced ice accretion. Note that the lower altitude points were outside of the tunnel calibration envelope. 
Note that these temperature conditions were simulated in the PSL facility to provide conditions appropriate to achieve ice accretion in the engine as a verification of the computer flow analysis code, as well as the capability of the PSL test facility to produce ice crystals at reduced altitudes.

\section{Example Data Point with No Ice Accretion (DP0902)}

Figure 12 shows the analysis results of DP0902 which is representative of an engine data point that did not experience ice accretion. The IWC at this point was the same as for the data point which did experience ice accretion. The results from the CD system model was utilized to provide the inlet flow conditions for the fan core and LPC simulation with the COMDES flow analysis code. The results of the CD engine system model and the measured values for key engine parameters at DP0902 compared well, and were on the order of 1\%, with the exception of air flow rate. Therefore the flow modeling with the COMDES flow code was considered to be an accurate representation of the actual conditions in the compressor at this data point.

The modeling results for the wet bulb temperature distribution and the ice particle melt ratio through the flow field were obtained from the computer flow analysis. The flow analysis for this data point, prior to ice cloud on, is illustrated in Figure 12. The computed values for wet bulb temperature at the targeted area (EGV tandem stator) were below that observed for the data points shown in Figure 8, and outside of the 7 Rankine range. Additionally, the flow analysis results indicate that the ice particle melt ratio was zero throughout the LPC flow field, thus there was no liquid water due to melting from elevated air temperature within the calculated residence time of the particles. Thus, the computer flow analysis of this data point corroborates the test result that the engine will not accrete ice.

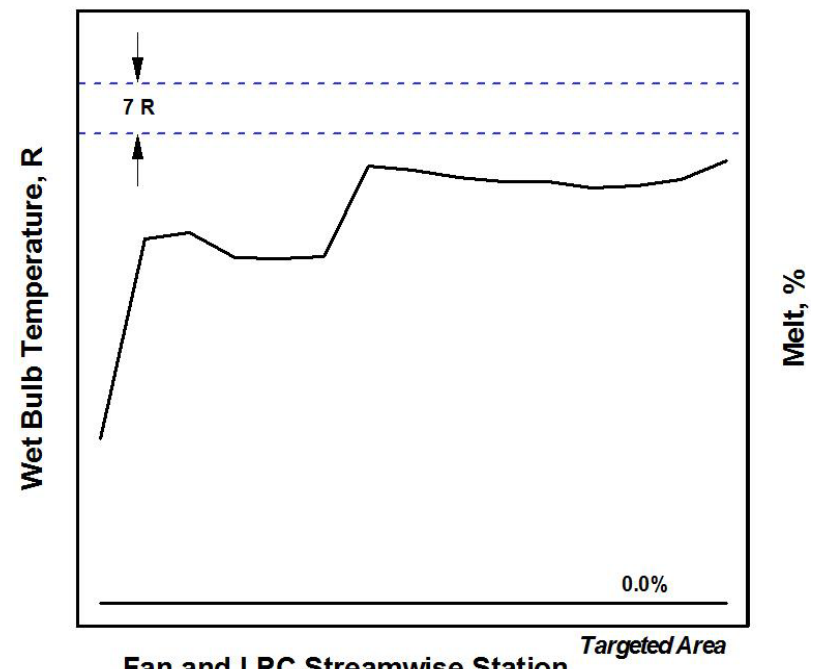

Figure 12: Flow analysis results of a data point (DP0902) which did not experience ice accretion, showing the wet bulb temperature outside the 7 Rankine range, and $0 \%$ ice particle melt through the targeted area.

The flow analysis results for data point DP0902, illustrated in Figure 13, show that both the static and total temperature of the air at the targeted area of the EGV were approximately 15 and 20 Rankine respectively lower than in the cases that experienced ice accretion. The flow analysis results also indicate that there was $0 \%$ melt, indicating that there was no liquid water due to heating of ice crystals by the air static temperature, within the calculated residence time. The EGV tandem stator metal temperature measurements at this data point are superimposed on the calculated air temperature plot in Figure 13, before the ice cloud was turned on, and are positioned between the calculated values of air static and total temperatures. This shows qualitatively that the air temperatures from the computational flow analysis are reasonable. The circumferential variation in measured metal temperatures, are indicated by the bars. After the ice cloud was turned on, the stator metal temperatures quickly decreased. However, after a considerable length of time, the engine did not experience ice accretion. 


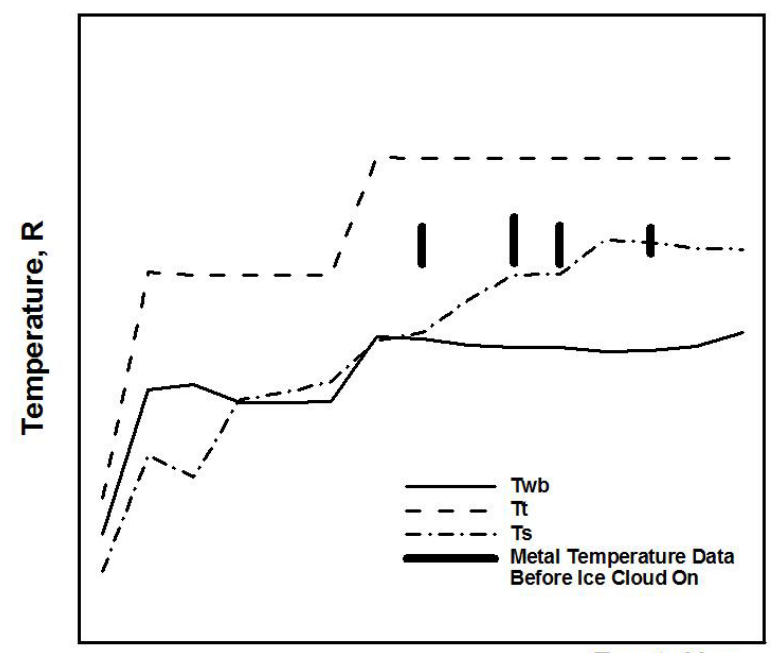

Fan and LPC Streamwise Station

Targeted Area

Figure 13: Data point with no ice accretion (DP0902); calculated wet bulb, static and total temperatures through fan core \& LPC, as well as the measured metal temperatures in the EGV.

Fan-Core and LPC Characteristic Map, with Data Points that Experienced Ice Accretion

Figure 14 is the characteristic map of the fan-core and LPC that was generated with the compressor flow analysis code, showing the pressure ratio versus corrected flow and percent of design corrected speed. The operating points where the engine experienced ice accretion were superimposed on the characteristic map. Note that the characteristic map represents the nominal compressor performance prior to ice accretion, and the data points represent the operating points where the engine experienced ice accretion.

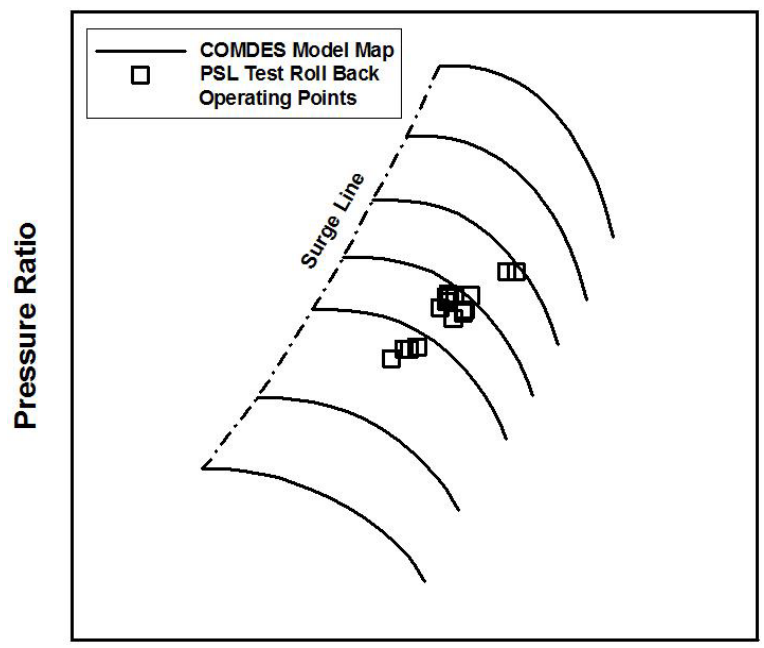

Flow Rate, corrected

Figure 14: Fan-core and LPC characteristic map, and the test data points where the engine experienced ice accretion.

The total, static, and wet bulb temperatures at the tandem stator 2 trailing edge, as calculated by the computer model for the engine data points with ice accretion, as well as the ambient engine inlet temperature, are shown in Figure 15. 


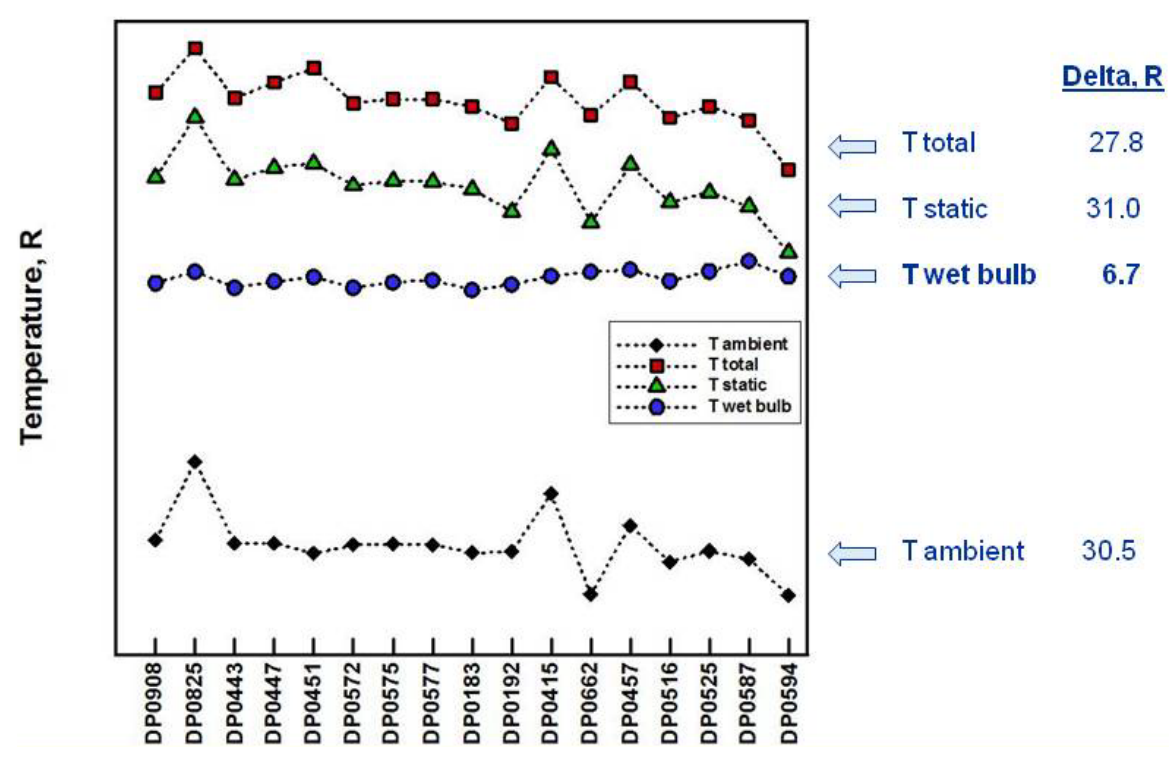

Figure 15: Static, total, and wet bulb temperatures at the EGV exit calculated by the computer model for the data points that experienced ice accretion, and the ambient temperature at engine inlet.

The calculated static temperature range is 31 Rankine, and the total temperatures range is 27.8 Rankine. However, the calculated wet bulb temperature is relatively constant as its range is on the order of 7 Rankine.

\section{Summary and Conclusion}

The purpose of this effort was to apply the analysis tool to assess the risk of ice accretion on a turbine engine that is known to have experienced engine icing events at known altitudes and operating conditions during flight through convective ice crystal clouds. The analysis tool consists of an engine thermodynamic cycle model, a compressor mean line flow analysis model that calculates the aerodynamic performance of each blade row, and an ice particle sublimation, melting and evaporation model that tracks the ice/water particle through the compressor blade rows. Two aerothermodynamic parameters that were previously identified as the criteria for determining whether there is a risk of ice accretion are the wet-bulb temperature and the ice particle melt ratio. This engine was tested in the Propulsion Systems Laboratory at simulated altitude operating conditions while ingesting a cloud of ice crystals. Ice accretion in the engine was successfully duplicated in the PSL at the known altitudes encountered during flight. In addition, the analysis tool was used to predict the conditions at other altitudes where engine icing could be expected. The engine was tested at these additional altitudes in the PSL and ice accretion in the engine was encountered, as predicted. This analysis considers only the source of liquid water due to the heating of the ice particle by the air through the heat of compression. Test data was selected for flow analysis from those operating points that represented ice accretion and no ice accretion in the engine. The flow analysis indicates that the engine experienced ice accretion when the ice crystals partially melt due to heating from the air, producing a non-zero ice particle melt ratio in the targeted area of the exit guide vane. In the cases where the engine did not experience ice accretion, both the static and total temperature of the air at the targeted area of the EGV were approximately 15 and 20 Rankine respectively lower than in the cases analyzed where ice accretion occurred. In addition, for the cases studied where there was no ice accretion, the flow analysis results indicate that there was zero ice particle melt ratio, indicating that there was no liquid water due to heating of ice crystals by the air static temperature, within the calculated residence time. The results from the computer simulation identified prevalent trends in wet bulb temperature, ice particle melt ratio, and engine inlet temperature as a function of altitude for predicting the risk of ice accretion in the engine due to ice crystal ingestion in the region of the targeted area. 


\section{References}

${ }^{1}$ Mason, J. G., Chow, P., Fuleki, D. M., "Understanding Ice Crystal Accretion and Shedding Phenomenon in Jet Engines Using a Rig Test," GT2010-22550.

${ }^{2}$ Mason, J. G., Grzych, M., "The Challenges Identifying Weather Associated With Jet Engine Ice Crystal Icing," SAE 2011-380094.

${ }^{3}$ Veres, J. P., Jorgenson, P. C. E., Wright, W. B., Struk, P., “A Model to Assess the Risk of Ice Accretion due to Ice Crystal Ingestion in a Turbofan Engine and its Effects on Performance", AIAA 2012-3038.

${ }^{4} J$ orgenson, P. C. E., Veres, J. P., Wright, W. B., May, R. D., "Engine Icing Modeling and Simulation (Part I): Ice Crystal Accretion on Compression System Components and Modeling its Effects on Engine Performance," SAE International, 2011-380025 .

${ }^{5}$ Veres, J. P., “Axial and Centrifugal Compressor Mean Line Flow Analysis Method,” AIAA-2009-1641, NASA/TM-2009215585.

${ }^{6}$ Wright, W. B., Potapczuk, M. G., and Levinson, L. H., "Comparison of LEWICE and GlennICE in the SLD Regime," AIAA-2008-0439.

${ }^{7}$ Wright, W. B., Jorgenson, P. C. E., Veres, J. P., "Mixed Phase Modeling in GlennICE with Application to Engine Icing," AIAA-2010-81093.

${ }^{8}$ Fowler, J. R., “GASPLUS User's Manual,” NASA LEW-15091, 1994.

${ }^{9}$ Struk, P., Currie, T., Wright, W. B., Tsao, J.-C., Broeren, A., Vargas, M., Knezevici, D., and Fuleki, D., "Fundamental Ice Crystal Accretion Physics Studies," SAE-11ICE-0034, 2011.

${ }^{10}$ Currie, T. C., Struk, P. M., Tsao, J.-C., Fuleki, D., Knezevici, D., "Fundamental Study of Mixed-Phase Icing with Application to Ice Crystal Accretion in Aircraft Jet Engines," AIAA-2012-3035. 



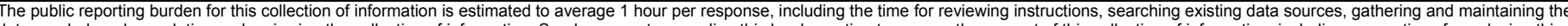
data needed, and completing and reviewing the collection of information. Send comments regarding this burden estimate or any other aspect of this collection of information, including suggestions for reducing this burden, to Department of Defense, Washington Headquarters Services, Directorate for Information Operations and Reports (0704-0188), 1215 Jefferson Davis Highway, Suite 1204, Arlington, VA 22202-4302.

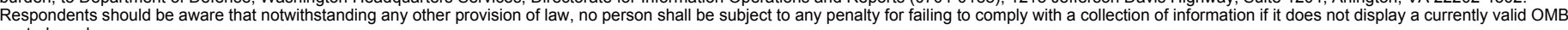

PLEASE DO NOT RETURN YOUR FORM TO THE ABOVE ADDRESS

\begin{tabular}{|l|l|l}
\hline 1. REPORT DATE (DD-MM-YYYY) & 2. REPORT TYPE & 3. DATES COVERED (FrOm - To)
\end{tabular}

01-10-2013

4. TITLE AND SUBTITLE

Technical Memorandum

Modeling Commercial Turbofan Engine Icing Risk With Ice Crystal Ingestion

5a. CONTRACT NUMBER

5b. GRANT NUMBER

5c. PROGRAM ELEMENT NUMBER

6. AUTHOR(S)

Jorgenson, Philip, C. E.; Veres, Joseph, P. 5d. PROJECT NUMBER

5e. TASK NUMBER

5f. WORK UNIT NUMBER

WBS 648987.02.02.03.20

\section{PERFORMING ORGANIZATION NAME(S) AND ADDRESS(ES)}

National Aeronautics and Space Administration

John H. Glenn Research Center at Lewis Field

Cleveland, Ohio 44135-3191

\section{SPONSORING/MONITORING AGENCY NAME(S) AND ADDRESS(ES)}

National Aeronautics and Space Administration

Washington, DC 20546-0001
8. PERFORMING ORGANIZATION

REPORT NUMBER

E-18797

\section{DISTRIBUTION/AVAILABILITY STATEMENT}

Unclassified-Unlimited

Subject Categories: 01, 07, 03, and 02

Available electronically at http://www.sti.nasa.gov

This publication is available from the NASA Center for AeroSpace Information, 443-757-5802

\section{SUPPLEMENTARY NOTES}

\section{ABSTRACT}

The occurrence of ice accretion within commercial high bypass aircraft turbine engines has been reported under certain atmospheric conditions. Engine anomalies have taken place at high altitudes that have been attributed to ice crystal ingestion, partially melting, and ice accretion on the compression system components. The result was degraded engine performance, and one or more of the following: loss of thrust control (roll back), compressor surge or stall, and flameout of the combustor. As ice crystals are ingested into the fan and low pressure compression system, the increase in air temperature causes a portion of the ice crystals to melt. It is hypothesized that this allows the ice-water mixture to cover the metal surfaces of the compressor stationary components which leads to ice accretion through evaporative cooling. Ice accretion causes a blockage which subsequently results in the deterioration in performance of the compressor and engine. The focus of this research is to apply an engine icing computational tool to simulate the

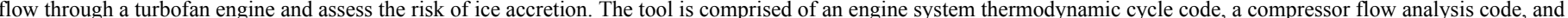
an ice particle melt code that has the capability of determining the rate of sublimation, melting, and evaporation through the compressor flow path, without modeling the actual ice accretion. A commercial turbofan engine which has previously experienced icing events during operation in a high altitude ice crystal environment has been tested in the Propulsion Systems Laboratory (PSL) altitude test facility at NASA Glenn Research Center. The PSL has the capability to produce a continuous ice cloud which are ingested by the engine during operation over a range of altitude conditions. The PSL test results confirmed that there was ice accretion in the engine due to ice crystal ingestion, at the

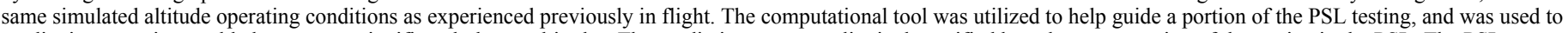
predict ice accretion could also occur at significantly lower altitudes. The predictions were qualitatively verified by subsequent testing of the engine in the PSL. The PSL test has helped to calibrate the engine icing computational tool to assess the risk of ice accretion. The results from the computer simulation identified prevalent trends in wet bulb temperature, ice particle melt ratio, and engine inlet temperature as a function of altitude for predicting engine icing risk due to ice crystal ingestion.

15. SUBJECT TERMS

Flow simulation; Turbine engine; Engine icing; Compressor

\begin{tabular}{|c|c|c|c|c|}
\hline \multicolumn{3}{|c|}{ 16. SECURITY CLASSIFICATION OF: } & \multirow{2}{*}{$\begin{array}{l}\text { 17. LIMITATION OF } \\
\text { ABSTRACT } \\
\text { UU }\end{array}$} & \multirow{2}{*}{$\begin{array}{l}\text { 18. NUMBER } \\
\text { OF } \\
\text { PAGES } \\
22\end{array}$} \\
\hline $\begin{array}{l}\text { a. REPORT } \\
\mathrm{U}\end{array}$ & $\begin{array}{l}\text { b. ABSTRACT } \\
U\end{array}$ & $\begin{array}{l}\text { c. THIS } \\
\text { PAGE } \\
\text { U }\end{array}$ & & \\
\hline
\end{tabular}

19a. NAME OF RESPONSIBLE PERSON

STI Help Desk (email:help@sti.nasa.gov) 19b. TELEPHONE NUMBER (include area code) 443-757-5802 

